the possible mixing up of the relics, but the excavations have been closely watched and studied by myself and several fellow-members of the local Archæological Society, and if there is one point clearer than another it is that there has been no such disturbance. The tree stumps in the overlying forest bed are as they grew, with their roots passing into the underlying strata, and everything indicates quiescence. Nor could the objects have sunk through the peat, for of the abundant stones in the overlying deposits, none have even penetrated the surface; the material is too compact to admit of this.

These interesting relics now form part of the extensive and ever-growing collection in the museum of the local Archæological and Antiquarian Society, the Société Jersiaise.

It would be interesting to know if any of your numerous archæological readers have found evidences of Neolithic man at this geological horizon.

Jersey, August 28.

J. Sinel.

The Structure of the Ciliary and Iris Muscles in Birds.

MAY I be allowed through your columns to direct the attention of physiologists and anatomists to certain special features in ocular accommodation, and in the movements of the iris in birds, and to a peculiarity of the ciliary muscle and sphincter of the pupil, which, so far as I have been able to ascertain, has not been previously described?

If the eye of any bird in which a light-coloured iris sharply contrasts with a black pupil be carefully watched, rapid changes in the size of the pupillary opening may be sometimes observed to take place during the few moments that the bird is fixedly looking at any object under the same intensity of illumination. Moreover, the character of these movements strongly suggests that they are under voluntary control.

The pupillary reaction to light is very rapid in birds; the recontraction following the transient dilation which accompanies the momentary closing and opening of the eyelids and nictitating membrane in the movement of blinking is so rapid that the contraction of the pupil seems to coincide with the re-opening of the eye, and not definitely to follow it as in man.

Atropine seems to have no effect in dilating, or Eserin in contracting, the pupil; neither does the former seem to affect accommodation in birds.

In connection with these facts it is also interesting to find that the ciliary muscle and the sphincter of the pupil in birds are both composed of striated fibres of the voluntary type, and not of plain unstriped muscle fibres as in man and other animals.

Thus, while in man with binocular vision the delicate movements of accommodation and the associated movements of the pupil are carried out by involuntary muscles, in birds, in which in many species vision is of the monocular type, the same movements are performed by voluntary muscles.

The extremely accurate and rapid movements of the beak in birds no doubt require a corresponding delicacy and rapidity of ocular accommodation at very short range.

Other interesting questions arise as to the representation of these intrinsic eye movements in the avian brain. The matter is also one of phylogenetic interest, and I hope to publish further histological details with photomicrographs of sections shortly.

Leicester, August 30 .

C. J. BOND.

\section{The Attacks of Birds upon Butterflies.}

Mr. Evershed's letter in NATURE of August 29 seems to me very suggestive, and it is to be hoped No. 2238 , VOL. 90] that his hypothesis may be tested by careful observation in many parts of the world. As regards the rarity with which these attacks have been witnessed in India by Mr. Evershed and many other naturalists, it is well to bear in mind the probability that the proportion of butterfly-eating birds differs in the different tropical regions. Indeed, it is difficult on any other hypothesis to understand why butterfly mimicry should be developed to such very different degrees in the three richest regions, being transcendent in the Neotropical, remarkable in the Ethiopian, but relatively poor in the Oriental region. Indirect evidence of the frequency of attacks in different areas might perhaps be obtained by a study of the relative amount of damage which could only have been inflicted by the beak of a bird.

St. Helens, Isle of Wight, August 26.

\section{A Flower-sanctuary.}

IN reply to Sir Edward Fry's inquiry (NATLRE, August 29, p. 66I) as to the powers of county councils to protect particular flowers, I am now enabled, through the courtesy of the clerk to the Cornwall County Council, to send a copy of the by-law referred to; it is given below. It is obvious that the Somerset County Council must possess the same powers as the Cornwall County Council, and that a by-law on these lines would meet the requirements of the case, and I venture to hope that Sir Edward Fry will exert his influence in favour of the enactment of such a by-law: Frank H. Perrycoste.

Higher Shute Cottage, Polperro, Cornwall, September 12.

County of Cornwall.-By-law for the Good Rule. and Government of the Administrative County of Cornwall, made in pursuance of the Local Government Act, I888, by the County Council of the said County, at a meeting held at Truro, on the 6th day of November, 1906, at which not less than two-thirds of the whole number of the Council were present:-

"No person shall (unless authorised by the owner or occupier, if any, or by law so to do) uproot or destroy any Ferns or other Wild Plants growing in any road, lane, roadside, waste, wayside bank or hedge, common, or other public place, in such a manner or in such quantities, as to damage or disfigure any such road, lane, roadside waste, wayside bank, or hedge, common or other public place. Provided that this by-law shall not apply to persons collecting specimens in small quantities for private or scientific use.

"Any person offending against this by-law shall be liable to a penalty not exceeding five pounds."

\section{THE SUMMER OF IOI2.}

THE summer of Igr 2 has proved so thoroughly unsummerlike, and has been so marked a contrast to the abnormally fine and hot summer of I9II, that a few facts may be of interest. The period dealt with will be limited to the three months June, July, and August.

The drought experienced in April, followed by a general deficiency of rain in May, rendered the early summer rains in June agreeable rather than otherwise, but the wet weather soon became too persistent, and the frequent rains have been a special feature of the past summer. With the exception of a period of eight days, July ro to $\mathbf{I}_{7}$, the weather throughout was unusually cold, and this was really the only dry period experienced over the country generally. 